\title{
Estrutura da riqueza do município de Pouso Alegre/Minas Gerais na transição dos séculos, $1870-1920$
}

\section{Structure of the wealth of the municipality of Pouso Alegre/Minas Gerais in the transition of the centuries, 1870-1920}

\author{
Fernando Henrique do Vale \\ Mestre em História Econômica pela Universidade de São Paulo, Licenciado em \\ História pela Universidade do Vale do Sapucaí. forma parte do Programa de Pós \\ Graduação em História Econômica da Faculdade de Filosofia, Letras e Ciências Humanas \\ (FFLCH-USP), Brasil \\ https://orcid.org/0000-0003-0837-1204 \\ ferdovale@yahoo.com.br
}

Fecha de recepción: 26 de noviembre del 2018

Fecha de aceptación: 15 de diciembre del 2018

Disponible en línea: 24 de mayo del 2019

Sugerencia de citación: do Vale, F. H. (2019). Estrutura da riqueza do município de Pouso Alegre/Minas Gerais na transição dos séculos, 1870-1920.

tiempo\&economía, 6(2), 37-57

doi: http://dx.doi.org/10.21789/24222704.1492

\section{RESUMO}

Com este artigo buscaremos entender como os habitantes do município de Pouso Alegre, Minas Gerais, se inseriram de certa maneira no processo de modernização e urbanização, analisando os inventários post mortem compreendidos entre 1870 a 1920. Este tipo de fonte nos oferece pistas para estudos econômicos e sociais, e com base na documentação inventarial, examinaremos a estrutura da riqueza local por meio de seus ativos, podendo comparar com 
outros municípios. Discorreremos também sobre as faixas de riqueza, o que nos possibilita entender cada uma delas e sua inserção na sociedade pouso-alegrense.

Palavras-chave: História Econômica, História Regional, Sul de Minas, Riqueza, Transição Códigos JEL: N76, R59

\begin{abstract}
With this article we will try to understand how the inhabitants of the municipality of Pouso Alegre, Minas Gerais, were inserted in a certain way in the process of modernization and urbanization by analyzing the post-mortem inventories from 1870 to 1920 . This type of source provides us with clues for economic and social studies, and based on the inventory documentation, we will examine the local wealth structure through its assets, and we will be able to compare it with other municipalities. We will also discuss the ranges of wealth, which allows us to understand each one of them and their insertion in the society of Pouso Alegre.
\end{abstract}

Keywords: Economic History, Regional History, South of Minas, Wealth,Transition

JEL Codes: N76, R59 
Com este artigo buscaremos entender como os habitantes do município de Pouso Alegre se inseriram de certa maneira no processos de modernização e urbanização, principalmente na passagem dos séculos XIx para o xx, momento em que o capitalismo inicia sua consolidação no Brasil. ${ }^{1}$ A formação de um mercado interno não foi linear, sendo marcada pela diversidade e diferença. E na região de Minas Gerais, podemos observar esta "diversidade" marcada pelas várias "Minas" em um mesmo estado, com características econômicas e sociais distintas. ${ }^{2}$

Com o esgotamento das exploração aurífera (em Minas Gerais), a economia mineira não sofreu retrocesso ou decadência. As fazendas que proviam essas regiões com os gêneros de primeira necessidade, começam a realizar comércio interprovincial, abatecendo principalmente a corte no Rio de Janeiro e tempos mais tarde a província de São Paulo (Lenharo, 1979). A economia do Sul de Minas, no entanto, é caracterizada pela variedade de produção. No caso do município de Pouso Alegre, no período em que estamos estudando, a sua inserção se deu em um sistema econômico de abastecimento regional para localidades que incorporam o mercado de exportação cafeeira: a diversificação da produção agropecuária, que atendia o próprio consumo, abastecia o comércio local, regional e interprovincial. O mercado local fornecia os gêneros às cidades e regiões vizinhas, principalmente aquelas que se dedicavam ao cultivo do café (como Ouro Fino, Jacutinga, Monte Sião), revelando a sua vocação direcionada ao comércio regional.

A transição do século xIx para o século xx também é marcada pelos processos de modernização e urbanização. Para Florestan Fernandes (1976, p. 149), a modernização é uma fase inerente ao capitalismo brasileiro, que se principia no século xIx. Nas palavras do autor, a modernização econômica dirigia-se no sentido de "estabelecer uma coordenação relativamente eficiente entre o funcionamento e o crescimento da economia brasileira e os tipos de interesses econômicos que prevaleciam nas relações das economias centrais com o Brasil", adaptando o meio econômico brasileiro a requisitos estruturais e funcionais de uma economia capitalista integrada, como já existia na Europa. Estas transformações favoreceram principalmente a elite, possuindo significados semelhantes aos comportamentos da aristocracia agrária, aprimorando os níveis de produção e de exportação que outrora foram alcançados pela grande lavoura fortalecendo o mercado interno. Dentro desta economia capitalista que se desenvolvia no Brasil, surge o elemento burguês, que diferentemente da elite agrária, habitava as cidades. As dinâmicas do mundo urbano possibilitam aos indivíduos

desenvolvimento do ser político, da vida cultural e religiosa cristalizadas entre as novas instituições urbanas das relações sociais e econômicas que tendem a se tornar mais complexas, entre mercados e ruas, resultantes do crescimento das cidades. (Saes et al., 2016, p. 15)

A transição do século xIx para o xx foi marcada também pela transformação nos padrões econômicos, uma necessidade do sistema capitalista. O modelo de produção industrial, que já vinha sendo exercido nos países capitalistas do centro, era algo que vinha sendo desenvolvido no sistema capitalista competitivo. No entanto, as regiões do mundo, que antes eram

1 O debate da transição ao capitalismo é bem denso e complexo, e pode ser retomado por meio da leitura de textos clássicos em Sweezy (1977).

2 O debate sobre a transição da economia no Brasil, em Minas e no Sul de Minas Gerais se encontra com grande ênfase na coletânea cf: Saes et al. (2012). 
tidas como colônias europeias, meras fornecedoras de matéria-prima, passariam a mercados consumidores, principalmente com a instituição do trabalho assalariado, consumindo produtos dos países centrais, e estabelecendo novos padrões de consumo.

Sobre o modelo capitalista que vinha se constituindo nos países periféricos, como no caso do Brasil, Celso Furtado expõe sua contribuição teórica mantendo certa semelhança a de Florestan Fernandes. A concentração de renda, presente principalmente nos países subdesenvolvidos, reforça a tendência para a reprodução de padrões de consumo de sociedade de muito mais elevado nível de renda média (Furtado, 1974, p. 26). Passamos então a entender o conceito de modernização para Furtado, quando são introduzidos "novos produtos à cesta dos bens de consumo" de uma minoria que passa a possuir renda maior que grande parte da sociedade. Ou seja, este grupo é definido pelo autor como uma minoria que vai ser tornando modernizada. Percebemos esta diferenciação e novas formas de consumo quando analisamos, principalmente, os inventários post mortem em Pouso Alegre, Minas Gerais. As pessoas que faziam parte da base da sociedade eram pequenos agricultores em sua maioria, possuíam entre os bens móveis, elementos básicos para o dia a dia, como catres, panelas, algumas roupas e ferramentas. Já, aqueles que compunham a classe intermediária e os mais ricos, possuíam maiores diversificações em suas formas de consumo. Nestas classes identificamos pessoas ligadas ao comércio, atividades liberais, serviços urbanos, médios e grandes fazendeiros. Em seus ativos móveis poderiam ser encontrados vestimentas, louças, pianos, livros, que geralmente eram importados de outros países, como também mobílias diferenciadas, objetos em ouro ou pedras preciosas, que enriquecia os hábitos de consumo destas classes. Além destas formas de consumir, estas classes tinham acesso a usufruir certas tecnologias que se tornavam padrões de consumo na sociedade brasileira na transição do século xIx para o xx, como a iluminação provinda da energia elétrica, a comunicação propiciada pelas linhas telefônicas, entre outros.

Como projeto político empreendido pelas elites brasileiras na transição do século xıx para o xx, a urbanização, fruto do capital agrário mercantil, fora responsável pelos melhoramentos e modernização, como a implantação de ferrovias e portos, e na infraestrutura do espaço urbano, abastecimento e saneamento, caracterizando-se também pela diferenciação nos padrões de consumo direcionados a "uma minoria, que está intimamente ligada à existência de um excedente. Sua rápida expansão na periferia é uma das consequências da ampliação do excedente possibilitada pela inserção no sistema de divisão internacional do trabalho" (Furtado, 2000, p. 85). Além das melhorias perceptíveis em torno do espaço, tal processo promoveu também alterações nos costumes e hábitos da população, introduzindo novas ideologias e novos valores originados das práticas civilizadoras e higienistas de origem europeia. Este projeto se tornou mais perceptível nos grandes centros urbanos, providos de

paisagens lineares, harmoniosamente estéticas, salubres e providas das ultimas inovações tecnológicas em termos de infraestrutura- mas que não dialogavam com o entorno imediato e ocultavam por detrás de suas quadras um padrão urbanístico e arquitetônico colonial, mostrando assim as contradições de um país ainda fortemente marcado pela desigualdade e pobreza. (Junior, 2007, p. 8)

Analisando o corpus documental, composto pelos inventários post mortem compreendidos entre 1870 e 1920, podemos compreender a sociedade pousoalegrense sob três aspectos: social, econômico e social. Este tipo de fonte, documentos ricos em informações que requer do 
pesquisador trabalho árduo, nos oferecem pistas para análises econômicas e sociais mediante a catalogação dos bens, aos quais podemos obter informações sobre as pessoas e suas vidas, constituição familiar, estrutura habitacional e objetos pessoais, podendo analisar o conjunto de uma sociedade.

Um estudo clássico que nos oferece grandes contribuições é o de Zélia Maria Cardoso de MeIlo. Em sua tese de doutorado Metamorfoses da riqueza. São Paulo, 1845-1895, com base na análise de inventários post mortem, faz uma análise de São Paulo do início do século XIX, momento em que estava sendo introduzido o cultivo do café. A sociedade, neste período, passava por transformações "na qual as formas tradicionais de riqueza começam a ceder espaço para as chamadas formas modernas de riqueza" (Lopes, 2016, p. 62). A partir da segunda metade do século xIx, por volta dos anos 1870, torna-se mais perceptível esta mudança, o mercado imobiliário passa a ser mais valorizado, principalmente com a queda da participação dos escravizados como um bem constituinte do patrimônio acumulativo. Outros ativos, chamados pela autora como abstratos, como o dinheiro, dívidas ativas, hipotecas, letras bancárias, principalmente nas capitais, constituiu nova forma do desenvolvimento da economia capitalista (Mello, 1985, pp. 89-90).

Para as décadas que compreendem nosso estudo, foram utilizados quatrocentos e sessenta e seis processos de inventários ${ }^{3}$ arrolados no município nos $1^{\circ}$ e $2^{\circ}$ Ofício da Comarca de Pouso Alegre, e para a escrita deste artigo, adotamos para a nossa análise trinta arrolamentos. Devemos levar em conta as limitações presentes neste corpo documental analisado. É importante salientar que o inventário não dá conta de um indivíduo, e para análise da sociedade em que este está inserido, torna-se essencial a incorporação das informações obtidas dos outros inventários e quantificá-las. Neste sentido, os ativos agrupados nos possibilita olhar para "formas de acumulação e de constituição de fortunas no tempo, possibilitando-nos acompanhar as mudanças que influenciam na constituição e diversificação destas fortunas" (Almico, 2011, p. 471), dando-nos condições de refletirmos sobre a parcela da sociedade que estão inseridas e as transformações ocorridas com o tempo.

Ao identificar a estrutura da riqueza da população pouso alegrense, por meio do montante maior resultante no arrolamento, podemos entender o destino em que se aplicava os investimentos locais em determinada década, identificando também as atividades que permitiram a acumulação das fortunas constituídas no município. Neste sentido, concordamos com Marcos Ferreira de Andrade, ao definir o termo fortuna, no sentido de se possuir "haveres, de bens, riqueza acumulada por algumas gerações... associadas a um leque diversificado de atividades, destacando-se o tipo social fazendeiro/negociante, que comercializava parte de sua produção" (Andrade, 2014, p. 21). Contudo, devemos ficar atentos quanto a definição de elite, pois a mesma pode possuir uma série de significados, fatores e situações, como por exemplo, um membro desta classe social não necessariamente poderia dispor de grandes quantidades de valores e bens, mas poderia estar inserido em alguma camada da sociedade que lhe concedesse prestígio. Para Flávio Heinz, "as elites são definidas pela detenção de um certo poder ou então como um produto de uma seleção social ou intelectual" (Heinz, 2006, p. 8), e a abordagem deste conceito nos direciona a determinar "quais os espaços e mecanismos dos poder nos diferentes tipos de socie-

3 O recorte temporal deste estudo está compreendido entre as décadas de 1870 a 1920, sendo que o levantamento deste corpus documental se estende até a década de 1920, por entendermos que a constituição de riqueza e bens especificados nos arrolamentos foram concebidos anteriormente ao ano abertura do processo. 
dade ou os princípios empregados para o acesso às posições dominantes" (Heinz, 2006, p. 8). E é sob este aspecto que definimos o termo "elites" para este estudo.

Seguindo estes parâmetros de análises, poderemos traçar o perfil das atividades econômicas rurais que eram exercidas no município de Pouso Alegre, e em qual ramo da produção agrícola se destacava. Já para a área urbana, ao analisarmos os comerciantes, adotaremos como base investigativa os registros de dívidas ativas e a declaração de bens móveis que poderia caracterizar certa atividade comercial, tomando conhecimento daqueles que exerciam a função de capitalistas. De nosso corpus documental composto pelos 466 processos inventariais, obteremos uma amostra de como se estruturava a riqueza dos moradores do município de Pouso Alegre.

\section{Formação da riqueza: os diversos tipos de bens}

Como já afirmamos ao iniciar um processo o inventariante declarava os bens que o inventariado acumulou durante toda a sua vida, fruto de aquisições ou heranças de familiares. Por meio de cada rubrica acompanhada de seus valores somados se obtinha o monte maior, e sendo subtraída as dívidas passivas e as custas processuais se constituía o monte menor que se repartiria com os herdeiros. A tabela abaixo nos traz informações sobre a porcentagem de riqueza dos moradores do município de Pouso Alegre em cada categoria de bens e a evolução da porcentagem ao longo das décadas estudadas.

Tabela 1. Investimentos nas categorias de bens nos inventários do município de Pouso Alegre, 1870-1920

\begin{tabular}{cccccc}
\hline \multirow{2}{*}{ Descriçāo } & \multicolumn{5}{c}{ Período } \\
\cline { 2 - 6 } & $\mathbf{1 8 7 0 - 1 8 7 9}$ & $\mathbf{1 8 8 0 - 1 8 8 9}$ & $\mathbf{1 8 9 0 - 1 8 9 9}$ & $\mathbf{1 9 0 0 - 1 9 0 9}$ & $\mathbf{1 9 1 0 - 1 9 2 0}$ \\
\hline Bens Móveis & $2 \%$ & $2 \%$ & $6 \%$ & $6 \%$ & $4 \%$ \\
\hline Bens Imóveis Rurais & $25 \%$ & $73 \%$ & $65 \%$ & $63 \%$ & $81 \%$ \\
\hline Bens Imóveis Urbanos & $2 \%$ & $2 \%$ & $6 \%$ & $18 \%$ & $14 \%$ \\
\hline Culturas & $1 \%$ & $1 \%$ & $2 \%$ & $0,4 \%$ & $0,1 \%$ \\
\hline Animais & $5 \%$ & $10 \%$ & $8 \%$ & $8 \%$ & $6 \%$ \\
\hline Escravizados & $22 \%$ & $10 \%$ & - & - & - \\
\hline Dinheiro & $1 \%$ & - & $3 \%$ & - & $0 \%$ \\
\hline Ouro e Prata & $0,2 \%$ & - & $0,1 \%$ & $1 \% \%$ & $3 \%$ \\
\hline Dívidas Ativas & $34 \%$ & $12 \%$ & $17 \%$ & $14 \%$ & $5 \%$ \\
\hline Dívidas Passivas & $7 \%$ & $8 \%$ & $7 \%$ & $12 \%$ & $100 \%$ \\
\hline Monte-Mor & $100 \%$ & $100 \%$ & $100 \%$ & $100 \%$ & - \\
\hline
\end{tabular}

Fonte: Inventários post-mortem da Comarca de Pouso Alegre 1870-1920. Disponível no Acervo do Museu Histórico Municipal Tuany Toledo e no Arquivo do Foro de Pouso Alegre (2a e 3a Varas Cíveis). Elaboração do autor.

Podemos caracterizar o município de Pouso Alegre como uma sociedade agrária, a partir da observação dos dados apresentados na tabela 1. Para a década de 1870, a porcentagem dos investimentos apresentavam valores baixos principalmente no ativo constante dos bens imóveis rurais, sendo observado para outros decênios um crescimento de quase $50 \%$ nos valores constantes. 
As dívidas ativas assinalavam 34\% dos valores encontrados na documentação para este decênio, ${ }^{4}$ ocupando o primeiro lugar de nossa tabela, tal fato que nos leva a refletir a importância do crédito e financiamento local no período estudado. Já em segundo lugar se apresenta a propriedade de cativos, representando $22 \%$ dos investimentos. Este valor apresentará queda na década de 1880, período este em que ocorrerá a abolição da escravatura, quando os investimentos passarão a ser realocados em outros ativos (sendo notados principalmente nas dívidas ativas, um crescimento de 5\% durante a passagem de 1880 para 1890). É importante observar, no tocante à vida no campo, a superioridade da criação de semoventes em relação ao cultivo de culturas. As diferenças de investimentos chegam a quase $10 \%$ entre as duas formas de atividades exercidas no município, constituindo como base da produção rural como subsistência e para o mercado.

A estrutura da riqueza nos aponta que a maior concentração de propriedades se encontra no espaço rural, tendo em vista que para o espaço urbano há um aumento de 12,29\% a partir da década de 1900. Na primeira década estudada, observamos que esta evolução nos investimentos se torna perceptível também nos registros de imóveis, momento este em que o meio urbano recebeu maiores cuidados e melhoramentos em sua infraestrutura. Contudo, torna-se interessante observar que a manutenção de propriedades rurais permanece predominante e possuiu um aumento $22,31 \%$ nas duas primeiras décadas do século xx, o que mantém o aspecto de ruralidade no município.

Em relação a outras localidades, podemos traçar alguns paralelos. Quando observamos os municípios de Campanha, Pouso Alegre e Varginha, vemos os ativos que apresentavam maiores números de ocorrências entre os três municípios.

Tabela 2. Número de ocorrências por tipo de ativos (1880-1899).

\begin{tabular}{ccccccc}
\hline \multirow{2}{*}{ Ativos } & \multicolumn{2}{c}{ Campanha } & \multicolumn{2}{c}{ Pouso Alegre } & \multicolumn{2}{c}{ Varginha } \\
\cline { 2 - 7 } & Ocorrências & $\%$ & Ocorrências & $\%$ & Ocorrências & $\%$ \\
\hline Bens Móveis & 126 & 95,45 & 210 & 76,64 & 76 & 93,83 \\
Semoventes & 114 & 86,36 & 216 & 78,83 & 59 & 72,84 \\
Escravizados & 84 & 63,64 & 39 & 14,23 & 15 & 18,52 \\
Imóveis Rurais & 110 & 83,33 & 253 & 92,34 & 64 & 79,01 \\
Imóveis Urbanos & 56 & 42,42 & 66 & 24,09 & 31 & 38,27 \\
Culturas & 61 & 46,21 & 59 & 21,53 & 31 & 38,27 \\
Dívidas Ativas & 74 & 56,06 & 110 & 40,15 & 29 & 35,80 \\
Dinheiro & 12 & 9,09 & 17 & 6,20 & 9 & 11,11 \\
Dívidas Passivas & 108 & 81,82 & 140 & 51,09 & 42 & 51,85 \\
\hline
\end{tabular}

Fonte: Pinheiro (2017, p. 148).

4 Se observarmos as outras décadas, percebemos que a porcentagem de dívidas ativas apresenta quedas de mais da metade dos valores apresentados para o decênio de 1870. Contudo, analisando o corpus documental para a respectiva década, temos que apenas uma pessoa concentrava um pouco mais de $30 \%$ do valor de dívidas ativas. Se subtrairmos o valor encontrado em seu inventário, temos que o total deste ativo corresponde a $8 \%$ dos investimentos para esta década. Na sessão relativa as dívidas ativas exploraremos este assunto. 
Ao analisar as três regiões, percebemos que a concentração da riqueza no município de Pouso Alegre se direcionava aos imóveis rurais e na criação de animais, e logo em seguida, a posse de bens móveis. As dívidas ativas também era um ativo de destaque entre as três localidades, o que nos demonstra a movimentação financeira por meio de empréstimos e a presença de negócios comerciais no município. A mão de obra escrava se concentrava mais em Campanha, cidade em que o apego à escravidão persistiu até a abolição, que diferentemente das outras cidades, a economia agrícola era fortemente baseada no trabalho escravo. ${ }^{5} \mathrm{Em}$ relação ao espaço urbano, a tabela acima nos apresenta Pouso Alegre com o maior número de ocorrências (66), em seguida Campanha (56) e Varginha (31). Mesmo possuindo quantidade um pouco maior de imóveis urbanos, os investimentos deste ativo no município de Pouso Alegre em valores ( $8 \%$ do valor da riqueza) ainda eram pequenos. O caráter rural é percebido nas três localidades, por meio da concentração de investimentos em propriedades no campo. Esta concentração também é percebida nos estudos empreendidos por Luciana Suarez Lopes (2017) sobre o município de Ribeirão Preto e de Fernando Antônio Abrahão (2015), ao abordar Campinas e região. Com referência a cidade de Lavras e seus distritos, Eduardo Vieira (2015) aborda em sua pesquisa que a acumulação de propriedades rurais se encontrava em sua maioria nas mãos da elite e que a maior concentração de riquezas, segundo o corpo documental levantado por este pesquisador, estava alocada nas dívidas ativas.

\section{Conceito de elite e faixas de riquezas local}

A elite pouso alegrense possuía características agrárias, justamente pelos seus investimentos estarem concentrando no meio rural, por meio de compras e manutenção de imóveis e propriedades rurais em grande número, como percebemos na amostra de inventários coletados para esta pesquisa. Ao contrário de algumas cidades da região do sul de Minas, como Alfenas, Guaxupé, Machado e Três Pontas, as quais se destacavam na produção cafeeira, Pouso Alegre mantinha uma diversificação de culturas. Maria Lúcia Prado Costa, ao se referir sobre a expansão cafeeira nas diversas regiões do sul da Província de Minas Gerais, principalmente em Alfenas e Pouso Alegre, nos aponta ter ocorrido na passagem da década de 1860 para 1870, mantendo investimentos em cafezais de porte considerável, empreendidos por fazendeiros há muito tempo estabelecidos nas terras sul-mineiras. ${ }^{6}$ Ao contrário do argumento de Maria Lúcia, em relação ao município de Pouso Alegre, por meio da análise da amostra de inventários, não se nota grandes extensões do cultivo da rubiácea ${ }^{7}$, apenas alguns produtores que

5 Podemos perceber isso observando os inventários para a década de 1880: para o município de Pouso Alegre, $70 \%$ dos inventariados arrolados já não possuíam escravos, enquanto que os 30\% possuíam até 5 escravos, distribuídos entre pequenos proprietários. Isso nos leva a pensar que "em parte, essa estrutura de posse pode representar um padrão de escravidão ligado ao mundo urbano, em que escravarias tendiam a ser menores e ligadas ao trabalho doméstico". Cf: Vale et al. (2016, p. 297).

6 Costa (2002, p. 19). A autora se baseia nos dados contidos no Almanaque Sul Mineiro para o ano de 1884.

7 Como bem sabemos, as pessoas que iniciavam um processo de inventário eram aquelas que possuíam um grupo de bens que resultava em um montante maior a ser repartido. Devemos ainda ter em mente que estes dados são relacionados apenas a pessoas que morreram, nos dando a ideia do número parcial de produção. Nos 466 processos analisados para o município de Pouso Alegre, encontramos registrados pequenas produções de café, o que denotava não ser o carro-chefe da economia local. Na sede municipal, foram encontra- 
mantinham em suas terras plantações que não ultrapassavam a 100 mil pés de café. Contudo, esta produção variada presente no município o torna uma sociedade de produção para abastecimento em meio a cidades que aos poucos investem na exportação.

O critério que utilizaremos para as observações nos ajudará a observar cada década. Utilizaremos de divisão por faixas de riqueza, baseado no método adotado por Thomas Piketty. Ao definir elites, o autor não estabelece barreiras entre as classes sociais, sendo que

toda representação da desigualdade fundamentada num pequeno número de categorias está fadada a ser esquemática e imprecisa, já que a realidade social subjacente é sempre de uma distribuição contínua. Em todos os níveis de renda e riqueza, há sempre um número de pessoas de carne e osso, cujas características e importância numérica varia de forma lenta e progressiva em função da estrutura de distribuição em uma dada sociedade. Não há rupturas descontínuas entre as diferentes classes sociais, entre o mundo do "povo" e os das "elites". (Piketty, 2013, p. 323)

Em seu método, o autor percorre por suas análises com conceitos estatísticos de décimos, classificando as faixas de riqueza em $10 \%$ mais ricos, $40 \%$ do meio e $50 \%$ da base. Com esta organização, tornava-se possível realizar comparações no tempo e no espaço, "sem deixar de lado as complexidades específicas dos povos e, principalmente, o caráter contínuo da desigualdade social". Para as análises que faremos durante as décadas, denominaremos para Pouso Alegre, os "mais ricos" aqueles que possuíam o montante final de seu inventário em contos de réis valores entre 50:000\$001 a 600:000\$000. Já para aqueles que compõem a posição intermediária tomamos como valores aqueles que possuíam o montante maior em torno de 2:000\$001 a 50:000\$000. A base constituinte da sociedade que estamos analisando se encontra no intervalo de riqueza que correspondem os valores até $200 \$ 000$ a 2:000\$000. Nesta etapa da análise, poderemos observar os diferentes sujeitos sociais que compunham cada faixa de riqueza e suas ocupações na sociedade pouso alegrense.

Afinal, quem eram aqueles que compunham a elite econômica no município de Pouso Alegre? Para entender esta composição, é preciso ter em mente os dados e informações que compõem as especificidades da localidade. Tomaremos como base de análise sobre a elite local as pessoas que compunham a faixa de riqueza dos "mais ricos", identificando aqueles que possuíam valores que estavam acima da metade de Manoel Moreira da Costa, correspondendo a $58 \%$ do valor extraído para este grupo, podendo ser observados na tabela 3.

dos sete processos em que declaravam a presença de pés de café nas propriedades rurais, com a quantia de 2.100 plantações. No distrito de Borda da Mata, haviam dez declarações contabilizando 27.169 pés, sendo o distrito com maior quantidade desta produção. Já em Estiva foram declarados 4.000 pés em seis inventários e no distrito de Sant'Ana dez produtores apontaram a existência de 3.500 plantas da rubiácea, totalizando nas declarações dos arrolamentos para as décadas estudadas 36.796 pés de cafés no município de Pouso Alegre. Segundo dados obtidos para a década de 1880 (tabela em anexos), Comarca do Jaguary possuía 254 fazendeiros cafeicultores e 3.370.000 pés de cafés. O município de Pouso Alegre, neste contexto, detinha apenas $4 \%$ da produção cafeeira da Comarca, sendo cultivadas por sete fazendeiros. As cidades de Jacutinga e Monte Sião detinham em torno de $80 \%$ do cultivo da rubiácea. Cf: Filetto (2000, p. 130).

8 Idem.

tiempo\&economía

Vol. 6 N. ${ }^{\circ} 2$ - Julio - Diciembre del 2019

p. 45

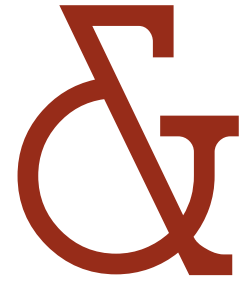


Tabela 3. Composição da Elite local por valores de fortunas (1870-1920).

\begin{tabular}{cccc}
\hline Ano & Inventariado & Localidade & Monte mor em Réis \\
\hline 1870 & Capitão Manoel Moreira da Costa & Pouso Alegre & $617: 498 \$ 974$ \\
1876 & Maria Modesta Marques Teixeira & Sant'Ana & $265: 996 \$ 000$ \\
1888 & Maria Carolina Rios & Pouso Alegre & $209: 502 \$ 175$ \\
1897 & Antônio da Costa Rios & Sant'Ana & $466: 952 \$ 714$ \\
1918 & Bárbara Maria de Oliveira & Congonhal & $216: 840 \$ 000$ \\
1893 & Coronel José Ignácio de Barros Cobra & Pouso Alegre & $228: 706 \$ 971$ \\
1920 & Herculano Olegário de Barros Cobra & Pouso Alegre & $220: 350 \$ 000$ \\
\hline
\end{tabular}

Fonte: Inventários post-mortem da Comarca de Pouso Alegre 1870-1888. Disponível no Acervo do Museu Histórico Municipal Tuany Toledo e no Arquivo do Foro de Pouso Alegre (2a e 3a Varas Cíveis). Elaboração do autor.

A tabela 3 nos mostra os valores das fortunas acumuladas durante a vida do inventariado em épocas diferentes, sendo colocadas por ordem de valores em contos de réis. Os sete inventariados acima foram identificados como os que possuíam as maiores fortunas durante o período analisado (correspondendo apenas $2 \%$ de todos os inventários analisados), podendo observar claramente no gráfico de dispersão 01 , em que colocamos todos os inventários que selecionamos para este estudo.

Gráfico 1. Composição da riqueza do município de Pouso Alegre 1870-1920 (em réis).

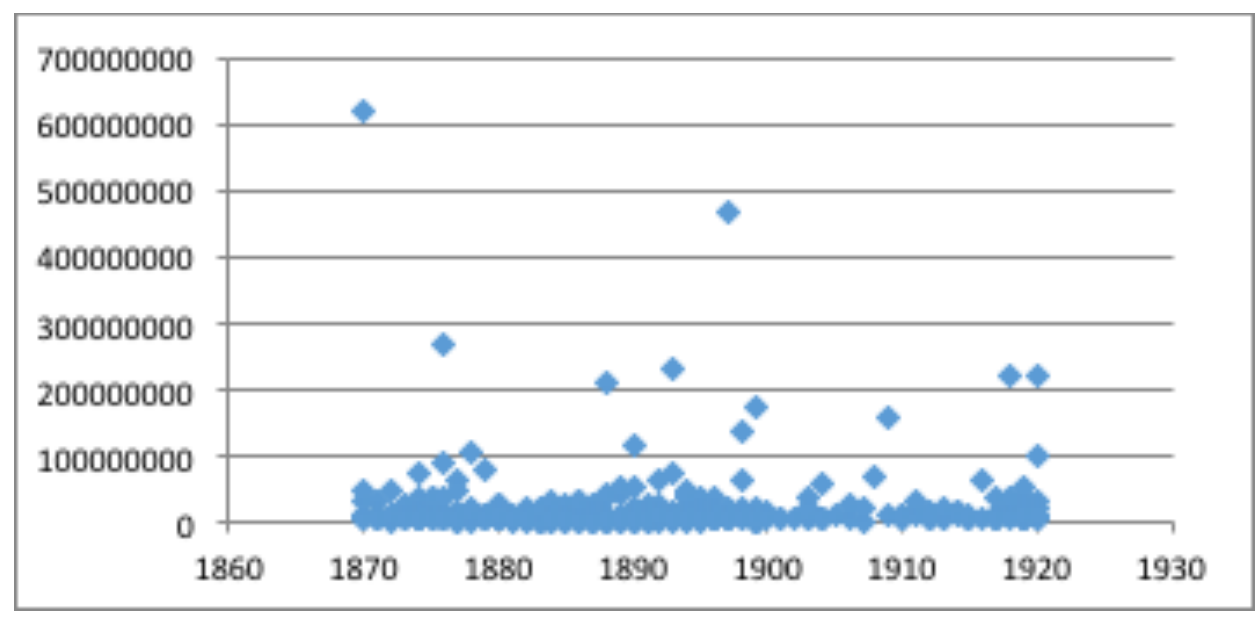

Fonte: Inventários post-mortem da Comarca de Pouso Alegre 1870-1920. Disponível no Acervo do Museu Histórico Municipal Tuany Toledo e no Arquivo do Foro de Pouso Alegre (2a e $3^{a}$ Varas Cíveis). Elaboração do autor

No gráfico 1 estão contidos os valores em contos de réis em forma de dispersão dos 466 inventários selecionados para este estudo, podendo notar quais os documentos que distanciaram da maioria da amostra. No eixo vertical encontramos os valores na moeda nacional, enquanto que no horizontal são constituídos a documentação de acordo com cada década. A maior concentração de renda dos inventariados no município de Pouso Alegre se encontram abaixo de 100:000\$000 réis, sendo percebidos na linha inicial. As maiores riquezas neste gráfico estão dispostas nas décadas de 1870 e 1890, em valores acima de 400:000\$000 réis, sendo 
que a faixa de riqueza correspondente pelos mais ricos percorrem por todas as décadas acima de 200:000\$000 réis. No primeiro plano deste gráfico, notamos que o monte mor do Capitão Manoel Moreira da Costa se encontra de forma elevada e logo em seguida em 1897 está a soma dos bens de Antônio da Costa Rios. Em conjunto com estes dois documentos, se encontram mais cinco inventários com riquezas acima estipulada para este grupo que compõem os mais ricos, pois se distanciam da concentração de renda local. Estas pessoas se distinguiam por possuírem investimentos em propriedades rurais (44\%) e por possuírem diversas rubricas de dívidas ativas (28\%). Possuíam nas propriedades rurais criações e plantações, e alguma propriedade no meio urbano. Os que se localizavam no meio urbano, geralmente eram comerciantes ou exerciam algum tipo de cargo público. Analisaremos na próxima seção o perfil da elite de Pouso Alegre, como também de cada faixa de riqueza composta pelos inventários selecionados.

\section{A composição social dos inventariados e o patrimônio constituído}

Com base em nossa documentação analisaremos nesta sessão as faixas de riqueza constituídas no meio social de Pouso Alegre e o patrimônio composto por cada grupo social no decorrer dos anos em que correram os processos, pelo critério dos $10 \%$ mais ricos, $60 \%$ do meio (classe intermediária) e 30\% constituintes da base. Dividiremos em três subseções para melhor organização do texto. Em um primeiro momento, trabalharemos com o grupo daqueles considerados os mais ricos, a chamada elite agrária local. Em seguida, observaremos a estrutura formada pelas faixas de riquezas que compunham o "meio" e a base do município.

\section{Os mais ricos: a elite agrária e seus investimentos}

A documentação analisada nos mostra que a elite por nós aqui proposta ${ }^{9}$ era constituída por um pequeno grupo de pessoas que possuíam padrões de consumo diferenciados, maiores acumulações de bens ou uma dinâmica econômica que possibilitava alguma forma de lucro. Quando obtemos o valor total dos montantes maiores constituídos dos 458 inventários analisados temos como importância a quantia de 7.347:337\$484 réis, sendo que a soma obtida dos documentos relacionados aos mais ricos correspondia a $46 \%$, ou seja, quase a metade da riqueza local estava concentrada em dezoito inventariados, $5 \%$ da população arrolada que compõe nosso corpus documental. A maior parte possuíam resididências tanto no meio rural como na cidade de Pouso Alegre, exercendo atividades como fazendeiros (exportador de gado, tropeiro), comerciantes, capitalistas, ${ }^{10}$ ou inseridos em alguma função ligada ao poder público, como vereador, juiz de paz e escrivão de órfãos. Títulos como capitão, major, alferes ou coronel eram comuns de serem concedidos aos sujeitos que compunham esta faixa de riqueza, como forma de distinção social.

9 Entenda-se o termo elite por nós empregado mediante os critérios por nós adotados, ou seja, aqueles que possuíam fortunas entre $£ 4.700,01$ a $£ 56.500,00$, compondo a faixa econômica dos "mais ricos".

10 Pessoa que tem grandes cabedaes e dinheiros para suas negociações, e meneio, banqueiro. "Fez-se outra contraliga de capitalistas, para com seus meneios abaterem o valor das apólices do banco". §O que vive de seus rendimentos. §O que empresta dinheiro a juros. Diz-se do que entra para uma sociedade com o capital necessário, havendo um ou mais sócios na indústria. (Silva, 1890, p. 405). 
Com a tabela 4 teremos a noção da distribuição de investimentos feitos pelas pessoas que compunham esta faixa de riqueza.

Tabela 4. Distribuição dos ativos entre os 10\% mais ricos do Município de Pouso Alegre, 1870-1920.

\begin{tabular}{ccc}
\hline & Composição da Riqueza- “Mais ricos” & \\
\hline Ativos & Valor em Réis & \% do Monte Mor Total \\
\hline Dinheiro & $69: 999 \$ 755$ & $2 \%$ \\
Bens Móveis & $96: 579 \$ 332$ & $3 \%$ \\
Ouro e Prata & $2: 860 \$ 730$ & $0,1 \%$ \\
Cultura & $33: 070 \$ 000$ & $1 \%$ \\
Animais & $182: 150 \$ 000$ & $5 \%$ \\
Escravos & $143: 520 \$ 000$ & $4 \%$ \\
Imóveis Rurais & $1.449: 142 \$ 662$ & $44 \%$ \\
Imóveis Urbanos & $142: 810 \$ 000$ & $4 \%$ \\
Dívidas Ativas & $966: 088 \$ 938$ & $29 \%$ \\
\hline
\end{tabular}

Fonte: Inventários post-mortem da Comarca de Pouso Alegre 1870-1888. Disponível no Acervo do Museu Histórico Municipal Tuany Toledo e no Arquivo do Foro de Pouso Alegre (2a e 3a Varas Cíveis). Elaboração do autor.

A tabela 4 nos mostra a distribuição dos ativos entre as pessoas que compunham o grupo dos mais ricos no município de Pouso Alegre. O maior ativo investido por estas pessoas eram as propriedades rurais, sendo $44 \%$ dos bens acumulados, estando estas aplicações em sua maioria acima de 150:000\$000 réis.

A segunda categoria em que encontramos maior incidência de valores mencionados em nossa documentação é a de dívidas ativas. Somando-se esta categoria temos que $29 \%$ destas pessoas exerciam a prática de emprestarem dinheiro ou ou realizar alguma venda a prazo (venda fiado), obtendo um certo lucro quando era feito a juros. Faziam parte deste grupo de credores pessoas que atuavam como capitalistas, no empréstimo de dinheiro e movimentações financeiras, como o Capitão Manoel Moreira da Costa. ${ }^{11}$ Na descrição de arrolamento de bens de Moreira da Costa, foram acumulados a soma de 541:607\$984 réis, correspondendo a $88 \%$ do montante maior de seu inventário. Foram descritas 75 pessoas que contraíram dívidas do inventariado, sendo que uma delas, encontrada no seu inventário correspondia a um investimento feito na firma de Barros Moreira Filho, este residente em Ouro Fino. Em sua descrição se refere a ser concernente a um capital livre e sujeito a liquidação por meio do último balanço feito no ano de 1870, no valor de 39:165\$750 réis.

As propriedades localizadas na área urbana eram bens presentes em todos os documentos da faixa que estamos estudando. Era comum que as pessoas mais abastadas possuíssem pelo menos uma propriedade na cidade, como forma de estar presente na dinâmica urbana local. Sendo $4 \%$ do montante maior dos inventariados, os valores declarados eram mais baixos em comparação com os imóveis rurais. Nos autos de Herculano Cobra, em 1918, possuía entre seus bens treze propriedades urbanas, no valor 50:000\$000 réis. Entre suas propriedades, sete

11 Inventário de Capitão Manoel Moreira da Costa, 1870. Disponível no Acervo do Museu Histórico Municipal Tuany Toledo. 
casas se localizavam no núcleo central de Pouso Alegre, sendo cobertas de telhas e assoalhadas, algumas contendo terreno anexo, três no núcleo do rosário e uma no distrito de Borda da Mata. Em seu documento não é mencionado a finalidade destas propriedades, porém, este grande número de propriedades e a prática de compra e venda nos dão pitstas de que esta forma de investimento era comum para a época.

Entre os animais e escravos, os ativos constituíam 9\% dos bens (sendo 5\% de animais e $4 \%$ dos cativos) pertencentes aos inventariados estudados. Apenas dois autos se inseriam nos anos da escravidão, o Capitão Moreira da Costa, possuidor de dezoito cativos (15:600\$000 réis, $3 \%$ dos bens arrolados), e Maria Marques Teixeira, proprietária de 50 escravos (48:570\$000 réis, $18 \%$ de sua fortuna). Nas propriedades constantes na documentação analisada, a criação de animais era variada, porém, o gado bovino se destacava por se encontrar em maior número (3138 cabeças), sendo que as maiores criadoras eram as fazendeiras Maria Modesta Marques Teixeira (492 cabeças) e Maria Carolina Rios (451 cabeças). Em menores proporções, nas terras desta elite agrária, se encontravam a criação de porcos (400), cavalos (196), muares (136), caprinos (190), e bois de carros (91). Estas criações atendiam o consumo próprio, local ou eram exportadas, porém em pequenas proporções, e os bois de carros, cavalos e muares, serviam para o transporte pessoal ou de alguma produção pertencente às fazendas e propriedades.

Os ativos menos investidos por este grupo eram a presença de dinheiro, bens móveis, metais preciosos e culturas. Era comum ter em caixa pequenas quantidades de dinheiro, para saldar custas do inventariado (como alguma dívida pendente, gastos com enterro e com a documentação do inventário). Os bens móveis e metais preciosos aparecem com menores valores. No entanto, percebemos, por meio da presença de alguns desses objetos, hábitos diferenciados de consumo entre as faixas de riqueza, como a posse jogos de refeição em louça, talheres em prata, livros, pianos, entre outros objetos de valor.

Percebemos que a dinâmica das pessoas que compunham esta faixa de riqueza era mais diferenciada, como um maior investimento na área rural e maior circulação do capital por meio de empréstimos e títulos públicos. Dos hábitos cotidianos, a começar de suas habitações (seja em suas fazendas ou casas na cidade) a vida dos negócios, eram sujeitos que se destacavam socialmente, por meio de algum título concedido, pelo cargo que dispunham na sociedade ou por possuir numerosas propriedades rurais, os tornavam constituintes de uma elite agrária local.

\section{O perfil econômico da classe intermediária local}

A faixa econômica do "meio" era composta por pessoas que atuavam em diversos ramos sociais, como fazendeiros, comerciantes, proprietários, sacerdotes, médico, professor, engenheiro, fiscal do município e alguns capitalistas, pessoas estas que se inseriam no rol dos duzentos e oitenta e sete inventários analisados, o que equivale a $60 \%$ de nossa amostra. Constituído por um grupo maior de pessoas arroladas, a soma de seus bens correspondia a $51 \%$ da riqueza local distribuídas de forma heterogênea. Mediante a tabela abaixo consideramos os investimentos feitos por este grupo de pessoas durante o período que estamos estudando. 
Tabela 5. Distribuição dos ativos entre os mais ricos do Município de Pouso Alegre, 1870-1920

\begin{tabular}{ccc}
\hline & Composição da Riqueza- “O meio” & \\
\hline Ativos & Valor em Réis & \% do Monte Mor Total \\
\hline Dinheiro & $93: 118 \$ 838$ & 2 \\
\hline Bens Móveis & $169: 927 \$ 025$ & 5 \\
\hline Ouro e Prata & $3: 596 \$ 640$ & 0,1 \\
\hline Cultura & $48: 051 \$ 900$ & 1 \\
\hline Animais & $296: 701 \$ 254$ & 8 \\
\hline Escravos & $417: 221 \$ 684$ & 11 \\
\hline Imóveis Rurais & $2.065: 169 \$ 041$ & 55 \\
\hline Imóveis Urbanos & $321: 533 \$ 040$ & 9 \\
\hline Dívidas Ativas & $375: 502 \$ 010$ & 10 \\
\hline
\end{tabular}

Fonte: Inventários post-mortem da Comarca de Pouso Alegre 1870-1888. Disponível no Acervo do Museu Histórico Municipal Tuany Toledo e no Arquivo do Foro de Pouso Alegre (2a e 3a Varas Cíveis). Elaboração do autor.

Como analisamos no grupo anterior, o maior investimento feito por esta faixa de riqueza se concentrou também nos imóveis rurais, variando entre duas a trinte e três propriedades descritas, de pequenas ou grandes proporções.

Os autos de Francisco das Chagas Fagundes nos mostra a variedade de produção em suas terras -o inventário de Francisco das Chagas Fagundes, 1916, disponível no Acervo do Fórum da Comarca de Pouso Alegre-. Os ativos correspondidos pelos bens imóveis rurais correspondiam a 92\% de sua riqueza (58:197\$000 réis). Nas propriedades de Francisco era possível encontrar campos de pastagens de capim gorduras (que serve de alimento de cavalos e muares, e para a engorda do gado bovino), um mangueiro para a engorda de porcos, moinho e uma casa com todo material de uma fábrica de polvilho em abandono. Percebemos que outrora suas atividades se diversificavam entre a criação de animais e a produção de derivados de mandioca. Em linhas gerais, por meio da análise da documentação que compõem esta faixa de riqueza, percebemos grande presença de produtores rurais que exerciam pequenas atividades em suas propriedades, sejam elas para o comércio ou consumo próprio.

A criação de animais e o cultivo de culturas, por esta faixa de riqueza, correspondia a 9\% dos investimentos feitos por esta classe média, tendo aqueles que possuíam maior número para o comércio e exportação, e outros, pequenos rebanhos destinados a consumo próprio. Dos 9128 animais contabilizados (8\% de investimentos) temos que grande parte se dedicava a criação de porcos (2877) e gado bovino (3904). Em dados mencionados nos almanaques corográficos sobre o Sul de Minas, o município de Pouso Alegre possuía número significativo relacionado ao comércio de porcos e de gado. Compunham em números o quadro de criação de animais no município por este grupo os caprinos (979), cavalos (911), bois para carro (603) e muares (350). Neste mesmo ambiente rural, o cultivo de culturas possuía o extrato de 1\% dos investimentos feitos por $23 \%$ dos inventariados inseridos neste grupo (48:051\$900), entre roças de milho, alqueires de arroz, canaviais e algumas plantações de café (que em muitas declarações apareciam como plantações velhas ou decadentes, pois como já mencionado, o forte do município de Pouso Alegre era a produção de diversos gêneros para o abastecimento, não apenas a concetração em uma só cultura). 
Os escravos correspondiam, no grupo da documentação estudada, a 11\% dos investimentos feitos. Entre as décadas de 1870 e 1880, foram registrados como propriedades destas pessoas 488 cativos, sendo que em geral, cada um possuía na média de um a cinco escravos. Já na década de 1880, as pessoas passam a possuir menos cativos, quantidade que chegava entre dois a cinco escravos por pessoas que possuíam.

As rubricas correspondentes às dívidas ativas para esta faixa de riqueza equivalem a 10\% da riqueza deste grupo. A maior parte dos valores eram de 1:000\$000 a 7:000\$000 réis, porém encontramos alguns (fazendeiros, capitalistas, engenheiro) que sobressaiam a esta variação, chegando a valores acima dos 10:000\$000 réis, como no caso do proprietário e Major Francisco Paula Duarte, cujos bens foram arrolados em 1877, mencionou-se a quantia de 20:415\$161 réis (46\% de seu montante final). Os empréstimos realizados por Francisco foram realizados por créditos, sendo nove o número de credores que lhe deviam determinada quantia -Inventário de Major Francisco de Paula Duarte, 1877, disponível no Acervo do Museu Histórico Municipal Tuany Toledo-.

A constituição de patrimônios imóveis no meio urbano seguia uma dinâmica que se opunha a faixa econômica dos mais ricos. Como observado na análise feita anteriormente, as pessoas que faziam parte desta elite agrária, detentoras das maiores fortunas, possuíam bens imóveis tanto no meio rural como no urbano. Dos 287 componentes deste grupo, apenas 80 possuíam alguma propriedade na cidade (28\%), em sua maioria entre 2 a 4 propriedades, mantendo imóveis em ambos espaços ou se estabelecendo unicamente no meio urbano. Em linhas gerais, percebemos que apenas $8 \%$ dos inventariados possuíam propriedades apenas no meio urbano, e exerciam atividades como comerciantes, padres, médico, engenheiro e políticos. Os outros $85 \%$ se concentravam no espaço rural, por não possuír capital para aquisição de outros imóveis ou por se dedicarem inteiramente ao campo, e alguns mantinham alguma edificação na cidade, reforçando o perfil agrário do município.

Os ativos expressos como bens móveis, dinheiro, ouro e prata geralmente dispunham de menos investimentos. Os metais preciosos equivaliam a $0,1 \%$ dos bens encontrados na documentação deste grupo, entre duas a quatro peças, e mesmo aqueles que detinham número maiores destes artefatos, não ultrapassavam a quantia de $500 \$ 000$ réis. Já aqueles que detinham posse de determinada quantia de dinheiro em espécie, possuía valores menores do que a faixa anteriormente analisada, com a mesma função mencionada, de saldar dívidas passivas e as custas do enterro e documentação do inventariado, sendo repartido entre os herdeiros a quantia remanescente. Os bens móveis, $5 \%$ dos investimentos, eram declarados por esta classe como os bens encontrados em suas residências, gêneros de negócio e mantimentos (carro de milho em casca, rolos de fumo, espigas de milho no paiol). Na residência de algumas pessoas deste grupo analisado era comum encontrar bens que os diferenciavam pelas formas de padrão de consumo.

Em linhas gerais, esta faixa de riqueza possuía pessoas que se inseriam tanto no campo como na cidade. A maioria dos inventários analisados pertencia a lavradores, que possuíam culturas diversas e criações para o próprio sustento e comércio. Identificamos também pequenos e médios fazendeiros, que possuíam maiores quantidades de terras e animais e pequenos plantéis de escravos (até o final da década de 1880). 
No espaço urbano, identificamos maior número de inventariados (que exerciam alguma função) do que na primeira faixa. Destes constam o arrolamento de dois sacerdotes, de um proprietário de uma fabrica de velas e um de uma fábrica de arroz, dois farmacêuticos, quatro proprietários (sendo um dirigente de um hotel), cinco capitalistas e quinze comerciantes, alguns profissionais liberais, como dois médicos, um advogado, tabelião, professor, diretor de colégio (Colégio São Sebastião), engenheiro e funcionários da municipalidade, subdelegado, juiz de paz, fiscal do município e agente do correio. A presença de uma elite urbana formada pelos profissionais acima e médios proprietários de terras, se diferenciava pelas grandes fortunas, porém se constituía na manutenção dos bens imóveis, da circulação monetária (a existência de alguns capitalistas) e de padrões de consumo diferenciados. Se na faixa anterior a figura do fazendeiro se sobressaía, a classe média era composta por profissionais autônomos, sacerdotes e comerciantes, pessoas estas que poderiam diferenciar do perfil de elite adotado para a análise anterior (em que nos baseamos pelas grandes fortunas), inseridos na dinâmica econômica local.

\section{A sociedade da Base}

A faixa econômica denominada como "base" da sociedade pouso alegrense era constituída por pessoas que possuíam como montante final do arrolamento de seus bens quantias que estavam em torno de $200 \$ 000$ a 2:000\$000 réis, valores encontrados em cento e cinquenta e três inventários de nosso corpus documental, correspondendo a 30\% da população por nós estudada. De pequenos fazendeiros e roceiros, faziam parte deste grupo alguns pequenos comerciantes, funcionário público (diretor de instrução), açougueiro, fabricante de velas, sacerdote e um tropeiro. O total dos monte- mor extraídos desta faixa corresponde a 3\% da composição da riqueza local, o que nos mostra que a concentração de renda local se encontrava principalmente nas mãos dos mais ricos e daqueles que possuíam as maiores fortunas. Podemos observar, na tabela 6, a composição da riqueza pertencente aos sujeitos que faziam parte da faixa de riqueza da base.

Tabela 6. Distribuição dos ativos das pessoas que compunham a "base" no Município de Pouso Alegre, 1870-1920.

\begin{tabular}{ccc}
\hline & Composição da Riqueza- “Base” & \\
\hline Ativos & Valor em Réis & \% do Monte Mor Total \\
\hline Dinheiro & $1: 900 \$ 500$ & 1 \\
Bens Móveis & $16: 603 \$ 752$ & 6 \\
Ouro e Prata & $227 \$ 500$ & 1 \\
Cultura & $2: 846 \$ 000$ & 13 \\
Animais & $37: 876 \$ 000$ & 1 \\
Escravos & $2: 525 \$ 000$ & 72 \\
Imóveis Rurais & $205: 089 \$ 320$ & 4 \\
Imóveis Urbanos & $11: 720 \$ 666$ & 4 \\
Dívidas Ativas & $10: 989 \$ 525$ & 4 \\
\hline
\end{tabular}

Fonte: Inventários post-mortem da Comarca de Pouso Alegre 1870-1888. Disponível no Acervo do Museu Histórico Municipal Tuany Toledo e no Arquivo do Foro de Pouso Alegre (2ª e 3a Varas Cíveis). Elaboração do autor. 
Os ativos compostos pelos imóveis rurais correspondiam aos maiores investimentos feitos também por aqueles que constituíam a base da sociedade. Estas pessoas, em sua maioria, possuíam entre dois a seis imóveis, sendo constituídos por partes de terras, casas e algumas benfeitorias.

A criação de animais correspondia ao segundo ativo mais investido, correspondendo a $13 \%$ do total obtido a partir do monte-mor dos inventariados, e sendo contabilizados 1120 animais para este grupo. Destes, 344 eram os suínos, 267 gados bovinos 195 cavalos, 193 caprinos, 107 bois de carro e 60 muares, valorizados em 37:876\$000 réis. Algumas pessoas se dedicavam a um ramo de criação de animais específico ou possuíam alguns que auxiliariam no trabalho diário. Percebemos que, diferentemente das outras duas faixas de riqueza analisadas, em que as dívidas ativas apareciam como um dos maiores investimentos feitos, os animais foram os bens que possuíam o segundo maior investimento em valores pelas pessoas que compunham a faixa econômica da base.

Os valores obtidos a partir da soma dos bens móveis resultaram em $6 \%$ da riqueza total deste grupo, constituídos principalmente por alguns mobiliários mais simples e utensílios utilizados no dia a dia. Os metais preciosos foram encontrados em nove inventários, sendo constituídos por alguns talheres (facas e colheres de pratas) e pequenas peças, como botões, medalhas, alfinetes, relicários, argolas e brincos de ouro ou prata. A distinção desta para as outras faixas de riqueza anteriormente analisadas, em relação aos bens móveis e objetos de metais preciosos, são as formas e padrões de consumo. Enquanto "os mais ricos" e "a classe média" possuíam objetos diferenciados, a maior parte das pessoas que compunham a base social dispunham de bens que atendiam suas necessidades diárias. As características dos bens móveis acumulados durante a vida das pessoas que faziam parte desta faixa de riqueza eram compostos por poucos objetos, mobiliários triviais e em alguns casos, instrumentos que indicavam a simplicidade vivida por estas pessoas e os afazeres que o inventariado poderia ter exercido em vida.

As dívidas ativas e a constituição de patrimônios no meio urbano compunham $4 \%$ da riqueza calculada para este grupo. Eram poucas as pessoas que detinham imóveis urbanos, e em suas posses concentravam não mais do que quatro propriedades. Os ativos que registraram os menores investimentos da "base" que constituía a sociedade de Pouso Alegre foram a propriedade de cativos, dinheiro e culturas, sendo que cada um correspondia a $1 \%$ do capital acumulado pelos inventariados. Foram mencionados, no grupo da documentação estudada, apenas cinco escravos, entre $200 \$ 000$ a $800 \$ 000$ réis, totalizando o valor de 2:525\$000 réis. Como os ativos acima, a posse de dinheiro em espécie também era escassa nesta faixa de riqueza, sendo poucos os que possuíam e em menores quantidades.

As culturas registraram a quantia de 2:486\$000 réis por meio da soma de toda a documentação, o que demonstra que poucos conservavam em suas propriedades rurais algum tipo de plantação ou cultivo (dos 153 inventários, apenas treze menções foram feitas), sendo mencionadas pequenas roças de milho, módicos plantios de mandioca, feijão, cana de açúcar e alguns pés de cafés.

A análise destas três faixas de riqueza (os 10\% "mais ricos", 60\% do "meio" e 30\% da "base") nos ajudou a fazer uma leitura e caracterizar de forma sucinta cada grupo e suas peculiaridades. Das poucas pessoas que detinham as maiores riquezas (quase a metade da fortuna local) que realizavam grandes investimentos na posse de terras (imóveis rurais) e mantinham 
casas na cidade, exercendo a função dos bancos, com empréstimos de dinheiro em forma de crédito e títulos, sustentando padrões de consumo diferenciados, a classe que estava no meio, um pouco mais da metade dos indivíduos analisados, sendo o intermediário dos padrões de riqueza, sujeitos que atuavam na área do comércio, empregados públicos e alguns na função religiosa, aproximavam-se dos mais ricos, o que nos mostra um certo equilíbrio entre estas duas faixas. Aqueles que integravam a base social, se caracterizavam por uma vida mais simples, caracterizados por possuir pequenas propriedades rurais, se dedicando na criação de animais e as suas pequenas plantações. As formas de consumo que dispunham se limitavam a objetos de primeira necessidade em suas casas ou para algum ofício exercido, não mantendo padrões de ostentação ou certos privilégios mantidos pelas outras faixas analisadas. Ė importante frisar que a amostra de documentos estudados se constituíam por famílias e/ou pessoas que possuíam algum bem, sendo que o município de Pouso Alegre possuía indivíduos mais pobres, que não fizeram parte do contexto de nossa análise.

\section{Considerações}

Este artigo se propôs a observar a sociedade de Pouso Alegre por meio das classes sociais e econômicas que a compunham. A utilização dos inventários, documentação rica em informações, nos deu pistas para realizar nossas análises. Percebemos que o perfil dos inventariados da elite era comum, ou seja, ligada ao meio agrário e por possuírem maiores valores em dívidas ativas. As pessoas que possuíam as maiores fortunas e aqueles que faziam parte da faixa de riqueza dos "mais ricos" não realizaram grandes investimentos nos serviços urbanos, frutos estes, em sua maioria, de iniciativas do governo, do município ou empresas privadas, distinguindo de outras cidades da região. Percebemos que ao longo das décadas estudadas, os maiores investimentos estavam alocados nos imóveis rurais, as pessoas, possuindo maiores ou menores posses, direcionavam a maior parte de sua riqueza as propriedades campesinas.

Ao examinar os ativos, observamos os padrões adotados em cada faixa de riqueza. Em relação os bens moveis, percebemos na maioria ser aqueles bens de primeira necessidade, e apenas uma camada da sociedade (alguns da faixa do meio e os mais ricos) possuíam padrões de consumo diferenciados. Considerando as culturas e os mantimentos, demonstramos, por meio da documentação, a variedade de produção no município, não se concentrando apenas no cultivo de uma cultura, mesmo não sendo uma das grandes fontes de riqueza os bens cultivados possuíam um certo espaço na economia do município. Em relação aos cativos, na primeira década estudada (1870) possuía grande porcentagem de investimento, e com o passar dos anos, próximos à abolição, no ano na década de 1880, este número vai caindo e sendo distribuídos para outros ativos, sobretudo nos imóveis e nas dívidas ativas. Com os estudos das categorias que compõem os bens a partir das anotações nos inventários, observamos algumas pessoas que se destacavam em certa maneira por possuir determinados bens ou investimentos. Como método de análise, utilizamos de divisões por faixa de riqueza instrumentalizada por Thomas Piketty, o qual faz a distinção em três classes: mais ricos, meio e base.

O perfil da elite em Pouso Alegre era comum, ligada ao meio agrário, e, diferentemente de outras cidades, principalmente aquelas que cultivavam e exportavam o café, os "mais ricos", tidos como grandes fazendeiros, não realizaram grandes investimentos nos serviços urbanos, 
que, no caso de Pouso Alegre, notamos ser frutos, em sua maioria, de iniciativas do governo, do município ou empresas privadas que já realizavam serviços pela região. Seus maiores investimentos estavam nas atividades rurais (imóveis e produção) e dívidas ativas, atuando como capitalistas, realizando movimentação de dinheiro. Já a classe intermediária ("meio"), composta por pessoas que atuavam em diversos ramos sociais, possuíam também maiores investimentos em imóveis rurais, constituídas em sua maioria por médias propriedades, em que se dedicavam ao trabalho com a terra, por meio da plantação e criação, ativo este que fazia parte de um dos maiores investimentos desta classe. Na cidade, atuavam como comerciantes, padres, engenheiros ou médicos. Se na elite a figura do grande fazendeiro sobressaía, nesta faixa de riqueza surge a figura do profissional autônomo. Já a população que compunha a faixa que classificamos como "base", tinha como maiores investimentos também os imóveis rurais, logo em seguida as dividas ativas e propriedades urbanas, e os menos investidos, escravos, culturas e animais. Se formos comparar o perfil econômico do município de Pouso Alegre com outras regiões, como Campanha e sua elite escravista (Andrade, 2008), Itajubá e seus investimentos em bens de raiz e dívidas ativas (Sobrinho, 2009), Alfenas, dedicada às atividades agropecuárias e ligada ao setor de abastecimento do mercado interno (Martins, 2012), Varginha, voltada para a produção de café (Ferreira, 2017), São João del Rei, com seus investimentos em dívidas ativas, apólices e imóveis urbanos (Filho, 2002) ou até mesmo Juiz de Fora, com um importante mercado consumidor interno e focalizada nas atividades urbanas e industriais (Giroletti, 1988), constatamos diferenças e similaridades. Se observarmos os ativos constantes nos inventários do município analisado, temos que, assim como São João del Rei e Itajubá, grandes investimentos se concentravam em dívidas ativas e imóveis rurais. Nas últimas décadas do século XIx e na transição para o século xx, a dinâmica local se estabelecia em torno das fazendas, predominantemente nas atividades rurais, principalmente como as de criação de animais e de cultura de gêneros alimentícios, tal como a cidade de Alfenas, itens estes que consistiam nos artigos centrais de exportação local. Em contrapartida ao município de Campanha, Pouso Alegre acompanhou as transformações propostas pela modernização assimilando de maneira equilibrada a passagem da mão-de-obra escrava para a livre no contexto da transição para o capitalismo no país. E em relação a Juiz de Fora, as atividades urbanas em Pouso Alegre se concentraram mais nas no exercício das práticas comerciais do que nas indústrias, e sua riqueza urbana se fortaleceu com o crescimento do comércio e dos investimentos empreendidos pela municipalidade. Se não podemos encontrar manifestações daqueles membros do grande capital urbano, por outro lado, a cidade não deixou de caminhar na construção de sua própria trajetória na assimilação do mundo urbano moderno.

\section{Referências}

Abrahão, F. A. (2015). A composição da riqueza em Campinas, 1870-1940. Artigo apresentado no XI Congresso Brasileiro de História Econômica e 12a Conferência Internacional de História de Empresas. Vitória: ABPHE.

Almico, R. de C. da S. (2011). Uma discussão metodológica sobre o crédito no século XIX. Passagens. Revista Internacional de História Política e Cultura Jurídica. Ano 3, vol. 3. Rio de Janeiro: setembro-dezembro. https://doi.org/10.5533/1984-2503-20113306

tiempo\&economía

Vol. 6 N. ${ }^{\circ} 2$ - Julio - Diciembre del 2019

p. 55 
Andrade, M. F. (2014). Elites regionais e a formação do Estado Imperial Brasileiro: Minas GeraisCampanha da Princesa (1799-1850). Belo Horizonte: Fino Traço.

Costa, M. L. (2002). Fontes para a história social do Sul de Minas: os trabalhadores de Paraguaçu e Machado (1850-1900). Belo Horizonte: Mazza Edições.

Fernandes, F. (1976). A Revolução Burguesa no Brasil - ensaio de interpretação sociológica. Rio de Janeiro: Zahar Editores.

Ferreira, N. S. (2017) Elite agrária e processo de urbanização: o município de Varginha- MG (18821920). Dissertação de Mestrado defendida no Programa de Pós-Graduação em História Econômica da Faculdade de Filosofia, Letras e Ciências Humanas. São Paulo: Universidade de São Paulo.

Filetto, F. (2000). Trajetória histórica do café na região sul de Minas Gerais. Dissertação de Mestrado apresentada na Universidade Federal de Lavras. Lavras.

Filho, A. de A. G. (2002). A Princesa do Oeste e o mito da decadência de Minas Gerais: São João del Rei (1831-1888). São Paulo: Annablume Editora.

Furtado, C. (1974). O mito do desenvolvimento econômico. São Paulo: Círculo do Livro S/A.

Furtado, C. (2000). Introdução ao desenvolvimento- Enfoque histórico- estrutural, $3^{\mathrm{a}}$ ed. Rio de Janeiro: Paz e Terra.

Giroletti, D. (1988). Industrialização de Juiz de Fora. Juiz de Fora: Editora da UFJF.

Heinz, F. M. (2006). Por outra história das elites. Rio de Janeiro: Fundação Getúlio Vargas.

Junior, J. G. S. (2007). Cenários de modernidade: os projetos urbanos das capitais brasileiras no início da República. In: Ill Fórum de pesquisa FAU. Mackenzie. São Paulo.

Lenharo, A. (1979). As tropas de moderação: O abastecimento da corte na formação política do Brasil (1808-1842). São Paulo: Edições Símbolo.

Lopes, L. S. (2016). A economia e a alocação de riqueza bruta em Ribeirão Preto (1899-1900). Revista História Econômica \& História de empresas, 19(1). https://doi.org/10.29182/hehe. v19i1.249

Lopes, L. S. (2017). Um estudo sobre a composição da riqueza de Ribeirão Preto com base nos inventários post-mortem (1866-1888). Disponível em: http://members.tripod.com/ Historia_ Demografica/pesquisadores/luciana/index.htm, acesso em novembro de 2017.

Martins, M. L., e Souza, A. S. (2012). Notas sobre as propriedades rurais de Alfenas/MG: décadas de 1860-1880. In: A. M. Saes e M. L. Martins. Sul de Minas em transição- A formação do capitalismo na passagem para o século 20. Bauru/SP: Edusc.

Mello, Z. M. C. (1985). Metamorfoses da riqueza: São Paulo, 1845-1895. Editora Hucitec, São Paulo.

Pinheiro, R. C. (2017). Trabalho, terra e capital no Sul de Minas em transição. Dissertação defendida no programa de Pós-Graduação em História Econômica da Faculdade de Filosofia, Letras e Ciências Humanas. São Paulo: Universidade de São Paulo.

Piketty, T. (2013). O Capital no século XXI. Rio de Janeiro: Editora Intrínseca. 
Saes, A. M., e Martins, M. L. (orgs.). (2012). Sul de Minas em transição: a formação do capitalismo na passagem para o século XX. Bauru/SP: EDUSC.

Saes, A. M., Gambi, T. F., Curi, L. F. B. (2016). O processo de urbanização no Sul de Minas em transição: Uma proposta de interpretação. In: A. M. Saes e M. L. Martins e Gambi, T. F. Sul de Minas em urbanização: Modernização urbana no início do século XX. São Paulo: Alameda.

Silva, A. de M. (1890). Diccionario da Lingua Portugueza, vol. I, Rio de Janeiro: Editora Empreza Litterária Fluminense. Disponível em: http://www2.senado.leg.br/bdsf/handle/id/242523.

Sobrinho, J. C. (2009). Negócios internos: estrutura produtiva, mercado e padrão social em uma freguesia sul mineiro. Itajubá- 1785-1850. Dissertação de Mestrado defendida. Juiz de Fora: Universidade Federal de Juiz de Fora.

Sweezy, Paul et al. (1977). A transição do feudalismo para o capitalismo. Rio de Janeiro: Paz e Terra.

Vale, F. H., Saes, A. M., Carvalho, R. R. da S. (2016). Pouso Alegre: uma economia de abastecimento numa sociedade exportadora. In: A. M. Saes et al. Sul de Minas em urbanização- Modernização urbana no início do século XX. São Paulo: Alameda.

Vieira, E. J. (2015). Produçao, comércio e acumulação de riqueza em um município escravista mineiro: Lavras/MG (1870-1888). Dissertação de mestrado em História Econômica. Faculdade de Filosofia, Letras e Ciências Humanas. São Paulo: Universidade de São Paulo. 